\title{
Supporting Regional Natural Resource Management (NRM) organisations to update their NRM plans for adaptation to climate change
}

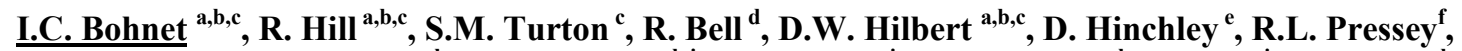 \\ J. Rainbird $^{\text {g }}$, P.-M. Standley ${ }^{\mathrm{h}}$, C. Cvitanovic ${ }^{\mathrm{b}, \mathrm{i}}$, G. Crowley ${ }^{\mathrm{j}}$, M. Curnock ${ }^{\mathrm{a}, \mathrm{b}}$, A. Dale ${ }^{\mathrm{j}}$, P. Lyons ${ }^{\mathrm{a}, \mathrm{b}}$, \\ C. Moran ${ }^{b, c}$, P.L. Pert ${ }^{\text {a,b,c }}$ \\ ${ }^{a}$ CSIRO Ecosystem Sciences, ${ }^{b}$ CSIRO Climate Adaptation Flagship, ${ }^{c}$ School of Earth and Environmental \\ Sciences, James Cook University, ${ }^{d}$ Reef Catchments NRM, ${ }^{e}$ Terrain NRM, ${ }^{f}$ ARC Centre of Excellence for \\ Coral Reef Studies, James Cook University, ${ }^{g}$ Torres Strait Regional Authority, ${ }^{h}$ Cape York NRM, ${ }^{i}$ Fenner \\ School of Environment and Society, Australian National University, ${ }^{j}$ Cairns Institute, James Cook \\ University. Email: iris.bohnet@,csiro.au
}

\begin{abstract}
Our paper presents an innovative co-research approach to addressing the challenges faced by Australian NRM organisations in managing the impacts of climate change on natural resources. The project involves four regional NRM organisations and researchers from two major research institutions. The four NRM organisations in the 'Wet Tropics Cluster' (WTC) are: (i) Reef Catchments NRM, (ii) Terrain NRM, (iii) Cape York NRM, and (iv) Torres Strait Regional Authority. They cover the major part of the far northeastern coastal region of Queensland, Australia. This region is recognised globally for its outstanding natural values and NRM organisations are responsible for meeting international obligations to manage and maintain the high biodiversity values as well as balancing a wide range of social, economic, cultural and environmental needs. In the face of a changing climate, NRM organisations are required to also incorporate planning strategies that are aimed at mitigating and adapting to the impacts of climate change. This project is aimed at supporting NRM organisations in their planning, first by establishing a 'Brokering Hub' for the WTC, which brings together researchers and NRM organisations to guide the work of the WTC and facilitate the development and communication of new knowledge and tools. The research component of the Brokering Hub is divided into three 'Science Nodes', one of which is the 'Participatory Scenarios and Knowledge Integration Node. (Figure 1). Our initial work in this Node has focused on the identification of focal issues and key drivers of change in the four NRM regions through a participatory process with members of the Brokering Hub. The results from this process have highlighted similarities and key differences between regions, indicating the specific scientific information needs required by each NRM organisation to develop potential climate adaption responses. In order to address the issues and information needs of NRM organisations, new knowledge and tools will be generated by the Science Nodes in collaboration with the NRM organisations. Our innovative co-research approach equips the regions well for this task.
\end{abstract}

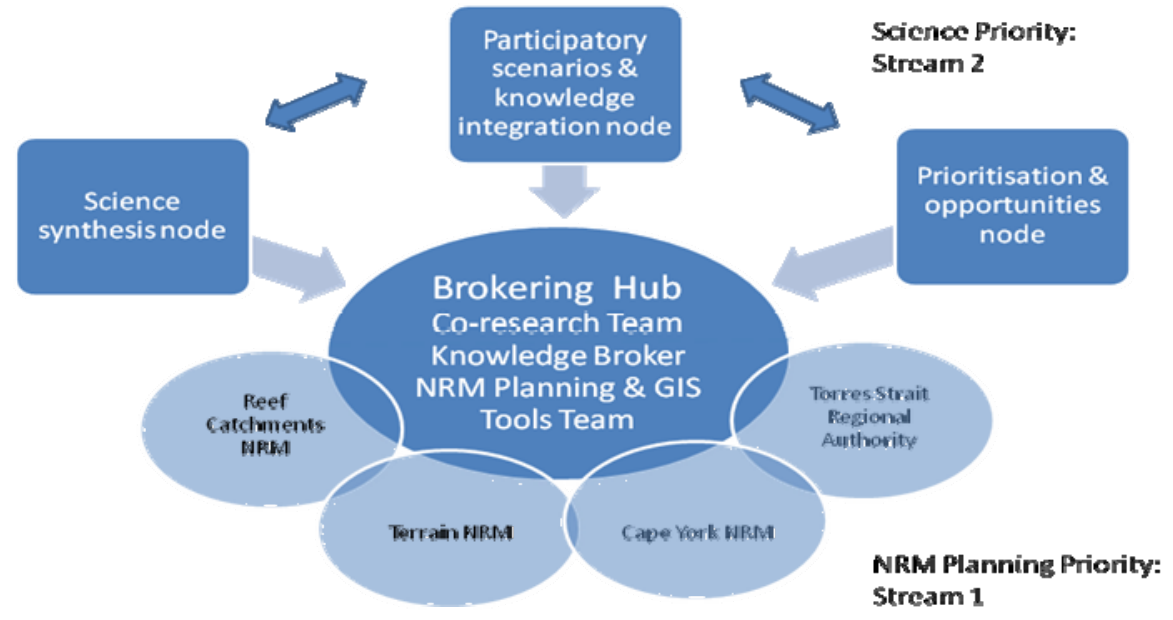

Figure 1. Co-research approach that promotes long-term system well-being and collective learning.

Keywords: Co-research, collective learning, knowledge broker, transdisciplinary research 


\section{INTRODUCTION}

In 2012 the Australian Federal Government committed \$44 million to Regional NRM Planning for Climate Change through its Clean Energy Future Plan (Australian Government, 2012). This funding supports regional NRM organisations to update their existing NRM plans in light of new scientific information about climate change impacts and adaptation strategies. In particular, the funding is intended to guide planning for climate change impacts on the land and to maximise the environmental benefits of carbon farming projects, for example by locating carbon farming projects where they also have benefits for maintaining biological diversity. In addition, funding is aimed at helping to guide where carbon farming activities (including biosequestration projects) should be located in the landscape to support biodiversity, water and agricultural production outcomes. Funding is divided into two streams: Stream 1 funding supports 54 regional NRM organisations to update their NRM plans by taking an adaptive management approach; Stream 2 funding supports coordination of research to develop scientific information at the regional-level and to generate new knowledge and tools required to develop the new and adaptive NRM plans. To add another layer of complexity, Stream 2 funding is divided into two elements: Element 1 funding supports delivery of regional climate projections for the whole of Australia. Element 2 funding supports research institutions to work with the regional NRM organisations to guide the application of information to adaptive NRM planning. Further complexity in the arrangements is the two 'funding streams' administered by separate federal government departments.

Australia's 56 NRM regions have been grouped into eight clusters through which Element 2 of Stream 2 is delivered. The eight clusters are based on some broad common characteristics such as land use, climate and how these are anticipated to change (Figure 2). In total, Element 2 of Stream 2 is comprised of nine projects, one for each of the eight clusters, and a National Project delivering cross-boundary regional level information on issues that are national in scale, such as changes to biodiversity and invasive species resulting from climate change.

Our paper focuses on four geographically distinct NRM regions grouped in the WTC, shown in Figure 2 in dark blue. These are the Mackay-Whitsunday, Wet Tropics, Cape York, and the Torres Strait regions, which are managed by Reef Catchments NRM, Terrain NRM, Cape York NRM, and the Torres Strait Regional Authority respectively.

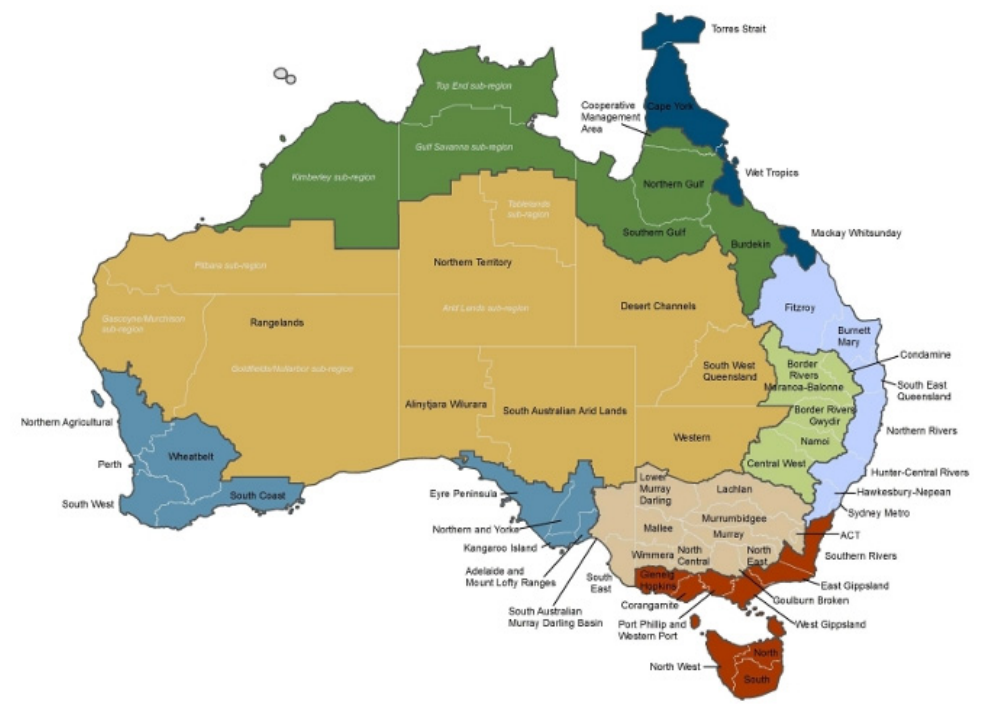

Figure 1. Australia's 56 NRM regions divided into eight clusters for delivery of Stream 2 projects.

We briefly introduce the importance of NRM climate adaptation in the WTC. We then present the coresearch approach implemented by the WTC that links the regional NRM organisations (Stream 1) with the research institutions and the National Project (Element 2 of Stream 2) through a Brokering Hub (Figure 1). Further, we describe the collaborative efforts undertaken by the WTC to date and focus on the activities carried out by the Participatory Scenario and Knowledge Integration Node. Co-identification of focal issues and key drivers of change in the four NRM regions has been one of the main activities, which highlighted the similarities and key differences between regions. We conclude the paper by arguing that addressing the region-specific issues and information needs will be a prerequisite to generate new knowledge and tools useful for the NRM organisations to update their NRM plans. Through our co-research approach we believe we are well equipped for this task. 


\section{THE WET TROPICS CLUSTER PROJECT}

\subsection{Context to NRM Climate Adaptation in the Wet Tropics Cluster Regions}

The WTC comprises a wide range of landscapes and seascapes including globally significant savannas, the vast majority of Australia's tropical rainforests, wetlands and low lying tropical islands. It also covers a high proportion of the Great Barrier Reef catchment, includes the Wet Tropics World Heritage Area (WHA), much of the Great Barrier Reef WHA and Cape York Peninsula where discussions are underway for a third WHA nomination. Arguably, the WTC supports a higher overall number of species than any of the other seven Australian NRM clusters, and includes many endemic flora and fauna species. Only the South West of Western Australia is richer in plant species.

The climate change threat to biodiversity has been especially well documented for the Wet Tropics rainforests (e.g. Hilbert et al., 2001; Williams et al. 2008). While much of the WTC's rainforest is in conservation reserves (especially the Wet Tropics WHA) some important areas are not, including many fragments and recovering forests on abandoned, previously cleared land. Management of off-reserve lands in response to climate change presents both important opportunities and potential threats to biodiversity (Dunlop et al., 2012).

Besides the very high biodiversity values in the WTC regions, there are substantial and significant economic and cultural values including tourism, agriculture, mining, fisheries, urbanisation, sea- and tree-change phenomena, and large areas of Aboriginal and Torres Strait Islander lands and seas (e.g. Bohnet and Pert, 2010). Much of the WTC's area is highly contested with multiple and sometimes conflicting demands for the region's natural resources. Climate change is likely to exacerbate these issues and create further challenges, since studies of climate change impacts and associated adaptation measures suggest significant changes in all land use sectors. Consequently, NRM planning will require consideration of climate change in future strategies for the regions in the WTC (Dale et al., 2013).

Management of the natural resources in the regions covered by the WTC is already contentious because of the dependence of multiple competing sectors on natural resources. The need for climate change adaptation in most of these sectors accentuates the challenge and requires an integrated approach (Dale et al., 2013). For example, both extensive and intensive primary production are likely to be challenged by climate change requiring changes to where, what and how food is produced in the region. The in turn will have important flow on effects on other sectors, and may increase the contest between sectors. However, there will be opportunities provided by the Carbon Farming Initiative (CFI), the Biodiversity Fund and other Caring for our Country Programs that could assist adaptation in the primary production sector while also favouring biodiversity conservation.

Traditional Owners are important inhabitants and land and sea managers in many areas of the WTC who are likely to be affected by climate change in numerous ways. The approximate proportion of Indigenous people to the total population in each region is $50 \%$ in Cape York, more than $90 \%$ in the Torres Strait and $12 \%$ in the Wet Tropics. Indigenous people, especially those living in remote areas of the WTC have a high sensitivity to climate change induced ecosystem change because of their close connection between 'healthy country' physical and mental well-being and their cultural practices (Green, 2006). Other over-arching issues affecting their community's welfare, such as health and poverty, are urgent and pressing and these will require strategies and policies to strengthen the adaptation capacity of such communities for climate-change responses (Petheram et al., 2010). Communities located on the low-lying islands of Torres Strait are particularly vulnerable to sea-level rise and increasingly intense storm surges caused by more extreme weather (Green et al., 2009).

\subsection{Co-Research Approach}

A critical factor underpinning the success of NRM is the generation and sharing of new information, as well as the capacity of end-users to learn from new information and adapt decisions accordingly (Armitage et al., 2008). However, despite a significant increase in the number of applied scientific publications (Ormerod et al, 2002), an implementation gap between science and management remains (Possingham, 2009). As such conservation managers continue to rely on individual experiences when developing and implementing conservation actions rather than evidence-based science (e.g. Cook et al., 2010), undermining the potential success of conservation actions. Not surprisingly, an extensive body of literature already describes the need for improved uptake of science into the decision-making process across most areas of NRM. 
One well recognised approach to improve knowledge transfer among scientists and end-users is through the co-production of knowledge, whereby decision-makers actively participate in scientific research programs from the onset, ensuring that the goals of the research are developed to meet their current requirements (e.g. Ceccarelli et al., 2011). Closer collaboration between decision-makers and academics will ensure that both groups have ownership over the information produced from the research and will also ensure that the research will have a direct application to both operational and decision-making processes. Accordingly, to ensure the success of this project we adopt a co-research approach, which brings together researchers and managers, different research institutions, and different scientific disciplines. Central to this approach has been the establishment of the WTC Brokering Hub, with members from research (Stream 2) and planning practice (Steam 1) (Figure 1). This co-research approach draws on the growing evidence that transdisciplinary research methods are of critical importance to solving sustainability problems and achieving climate adaptation (e.g. Jahn et al., 2012; Lang et al., 2012). The Brokering Hub consists of two project leaders who coordinate and manage the activities of the WTC, representatives from each of the four regional NRM organisations, a member of the National Project team, and researchers representing the three science nodes: (1) science synthesis, (2) participatory scenario and knowledge integration, and (3) prioritisation and opportunities (Figure 1). The Brokering Hub is the main decision-making group driving the activities undertaken by the WTC.

In addition, the Brokering Hub is supported by a dedicated knowledge broker, another well recognized approach to improve the transfer of knowledge among scientists and end-users. While the exact role and function of knowledge brokers are conceptualised and operationalised differently in various sectors and settings, the key feature of such a role is to facilitate the exchange of knowledge between and among all stakeholders. For the purpose of the WTC, the knowledge broker supports the members of the Brokering Hub to develop strategic linkages and facilitates two-way communication between researchers and NRM organisations around climate impact science and climate adaptation planning. This also involves working with the NRM groups to understand their exact and individual information needs and articulating them back to the science teams. In turn, the knowledge broker must also translate high-level science into products and tools that can be effectively implemented on the ground by the various NRM groups. This role is vital to ensure that plans dealing with the biodiversity impacts of climate change capitalise on opportunities, including those provided by the CFI and the Biodiversity Fund. Regular Brokering Hub meetings ensure that the research and advice provided by the three science nodes inform each other, are of high quality, and will be in a communicative form that meets the NRM planners' needs (Figure 1). Additionally, these meetings provide a mechanism for co-research undertaken by the WTC project to inform work undertaken by the National Project to ensure that this work complements and adds value to the activities undertaken by the WTC.

The Brokering Hub aims to establish an adaptive network and ongoing cyclic planning system that promotes collective learning between the WTC NRM organisations and its research providers through co-research. The three science nodes in this project are distinct co-research projects, which consist of project teams whose members have diverse disciplinary backgrounds and scientific expertise in the NRM regions. However, the three science nodes are organised to inform each other in order to cover the broad range of questions that need to be addressed within NRM planning (Figure 1). Outputs from the three science nodes will include reports and data products that synthesise available information and science gaps (science synthesis node). Scenarios will integrate scientific, local and Indigenous knowledge that support collective learning (Participatory scenarios and knowledge integration node). Spatial products, data and indicators will support the NRM organisations in developing their GIS platforms for collaborative prioritisation of ecosystem services within landscapes and for prioritisation of efforts into adaptation pathways that can maximise opportunities (Prioritisation and opportunities node).

\subsection{Collaborative Efforts}

The diversity of issues requiring attention within regional NRM planning for a changing climate are complex (e.g. Dale et al., 2013). The co-research approach taken by the WTC responds to this complexity and enables alignment of efforts and opportunities for collective learning between the four NRM organisations and the three research teams that are part of the WTC. There is growing evidence that collaboration is vital to overcoming institutional fragmentation, uncertainty and contested interests that characterise and bedevil efforts to achieve sustainable NRM (Lane et al., 2009) Fortunately, there is, in addition to the national projects which deliver regional-level information to the WTC via knowledge brokers, a further major National Environmental Research Program (NERP) focusing on Tropical (and other) Ecosystems in northeastern Australia (NERP, 2012). Research undertaken through NERP is closely aligned with the co-research undertaken by the WTC. 
Participatory workshops have been held to identify existing knowledge and processes and gaps in these. First, a one-day workshop was held under the auspices of both the WTC and the NERP project 'Science integration into regional planning' bringing together those undertaking climate change research and planning for regional NRM (Crowley et al., 2013). The workshop included the 'Monsoon North Cluster' as well as the WTC, to promote cross-regional and cross-cluster collaboration. The workshop participants mapped common planning elements across the NRM regions and identified current cross-regional research/co-research projects aimed at supporting NRM regional planning. This exercise contributed to the identification of knowledge gaps and highlighted the importance of the three science nodes of the WTC which provide diverse and foundational science for implementation in NRM planning.

Second, a half-day workshop for WTC Brokering Hub members was led by the 'Participatory Scenario and Knowledge Integration Node'. The workshop identified the focal issues and drivers of change in the four NRM regions. Through this workshop participants gained a shared understanding of the focal issues (Table 1) and drivers of change (Table 2) in each of the NRM regions of the WTC. Further, based on the identification of issues common across the WTC and those specific to NRM regions, discussions can now be progressed between the researchers of the 'Participatory Scenario and Knowledge Integration Node', the knowledge broker, and NRM planners on next steps in the development of scenarios to inform the new NRM plans (e.g. Bohnet, 2010; Bohnet et al., 2011; Pert et al., 2013).

Table 1. Focal issues in the four NRM regions.

\begin{tabular}{|l|l|l|l|}
\hline \multicolumn{5}{|c|}{ What are the focal issues in your region? } \\
\hline Mackay/Whitsunday Region & Wet Tropics Region & Cape York Region & Torres Strait Region \\
\hline Coastal development & $\begin{array}{l}\text { Habitat condition and } \\
\text { connectivity }\end{array}$ & $\begin{array}{l}\text { Water availability } \\
\text { (groundwater) }\end{array}$ & $\begin{array}{l}\text { Sea level rise - erosion, inundation and } \\
\text { loss of coastal habitat and infrastructure }\end{array}$ \\
\hline Expanding port development & $\begin{array}{l}\text { Urban development } \\
\text { patterns }\end{array}$ & $\begin{array}{l}\text { Tree cover/clearing } \\
\text { Vegetation condition (fire) }\end{array}$ & $\begin{array}{l}\text { Ocean acidification - loss of marine } \\
\text { ecosystems and resources }\end{array}$ \\
\hline Projects of state significance & $\begin{array}{l}\text { Productivity of } \\
\text { agriculture, tourism, } \\
\text { fisheries }\end{array}$ & $\begin{array}{l}\text { Shift in fires (longer } \\
\text { dry/shorter wet season), } \\
\text { fragile soils }\end{array}$ & Ocean temperatures - heat stress \\
\hline $\begin{array}{l}\text { Skepticism about climate } \\
\text { change }\end{array}$ & & $\begin{array}{l}\text { Access (ease \& } \\
\text { challenges)/ infrastructure }\end{array}$ & Temperature - health, livability \\
\hline $\begin{array}{l}\text { Highly variable rainfall - } \\
\text { increased risk of storm surge }\end{array}$ & $\begin{array}{l}\text { Coastal planning and } \\
\text { development }\end{array}$ & $\begin{array}{l}\text { Evaporation rates - impact on water } \\
\text { resources }\end{array}$ \\
\hline & & $\begin{array}{l}\text { Maintenance and } \\
\text { diversification of } \\
\text { livelihoods }\end{array}$ & $\begin{array}{l}\text { Shift in rainfall - change in vegetation, } \\
\text { impact on agri-culture and water } \\
\text { availability }\end{array}$ \\
\hline
\end{tabular}

Table 2. Key drivers of change in the four NRM regions.

\begin{tabular}{|l|l|l|l|}
\hline \multicolumn{5}{|c|}{ What are the key drivers of change in your region? } \\
\hline Mackay/Whitsunday Region & Wet Tropics Region & Cape York Region & Torres Strait Region \\
\hline $\begin{array}{l}\text { Mining, sugar, grazing and } \\
\text { tourism sectors }\end{array}$ & $\begin{array}{l}\text { Economic priorities (allocation to the } \\
\text { business as usual ) }\end{array}$ & Mining sector & $\begin{array}{l}\text { Climate change in itself (key } \\
\text { stressor) }\end{array}$ \\
\hline $\begin{array}{l}\text { Local and state policies (which } \\
\text { are changing) }\end{array}$ & $\begin{array}{l}\text { Demographics in agriculture (average } \\
\text { age of farmer is over 55) }\end{array}$ & $\begin{array}{l}\text { Tree clearing (large } \\
\text { scale) }\end{array}$ & $\begin{array}{l}\text { Peak oil - economic pressures } \\
\text { (energy production, } \\
\text { agriculture) }\end{array}$ \\
\hline $\begin{array}{l}\text { Population growth - impacts on } \\
\text { urban and peri-urban regions, } \\
\text { decrease in land available for } \\
\text { agriculture }\end{array}$ & $\begin{array}{l}\text { Willingness to outsource decline (less } \\
\text { developed countries pay the } \\
\text { environmental/social costs of our } \\
\text { lifestyles/choices) }\end{array}$ & $\begin{array}{l}\text { Uncoordinated and } \\
\text { politicised agendas }\end{array}$ & Demographic changes \\
\hline
\end{tabular}

Common focal issues relating to climate change across all NRM regions include:

- Sea level rise and associated erosion, inundation and loss of coastal habitat and infrastructure

- Increase in ocean temperatures and associated heat stress of marine ecosystems and resources

- Ocean acidification and associated loss of marine ecosystems and resources

- Increase in temperature and associated impacts on health and liveability

- Shift in rainfall and associated changes in vegetation and impacts on agriculture and water availability

- High evaporation rates and associated impacts on water resources.

The effects of these issues are likely to be experienced very differently in each of the four NRM regions. However, this will also depend heavily on how the Australian, State and Local Governments respond to these challenges. For example, Australia's peak coastal groups, which include the National Sea Change Taskforce and the Queensland regional NRM Groups Collective, have joined forces in the lead up to the September 2013 Federal election to campaign for a co-ordinated national coastal policy (National Sea Change Taskforce, 2013). 
The process of developing scenarios for NRM planning outcomes will involve consideration of how focal issues are being addressed in each NRM region, how they interact, and key drivers of change. For example, in the Torres Strait, Injinoo people have observed environmental changes including extensive coral bleaching episodes, changes to marine resources available in certain seasons, and loss of favourite beach camping sites and coastal shade trees (McIntyre-Tamwoy et al., 2013). From these experiences and the fact that the Torres Strait Islands are low lying, their short, medium and long-term responses and adaptation preferences are likely to be very different when compared to the other three NRM regions. In the Mackay-Whitsundays Region, for example, where skepticism about the occurrence and cause of climate change among landowners has been identified as a focal issue, along with development pressures, it will be difficult to effectively address coastal development issues through regional NRM planning alone. Such difficulties are exacerbated where state planning processes have changed to the extent where increasing intensity of extreme weather events is not acknowledged and NRM planning does not need to be acknowledged in assessing development approvals.

\section{DISCUSSION AND CONCLUSIONS}

The co-production of knowledge and the use of knowledge brokers are often cited as mechanisms to improve the transfer of knowledge between scientists and end-users; however, few examples exist of where these approaches have been jointly operationalised. Here, we provide a case study of the importance of these roles in achieving improved information flow between researchers and on-ground managers. Specifically, the coresearch approach taken by the WTC and supported by the knowledge broker enables collaboration between science and practice, different scientific disciplines, multiple levels of governance, and multiple spatial scales. For these complex types of collaboration to be effective, the process requires careful and considerable coordination and communication. Our governance and co-ordination through the Brokering Hub enables collaboration between members to identify issues, existing information and remaining knowledge gaps and needs, as well as processes through which those gaps and needs will be filled.

The primary step in this process has been the development of a shared understanding among the members of the Brokering Hub about the common and specific issues that the four NRM regions in the WTC face. Such shared understanding it is a prerequisite for agreeing on issues NRM organisations can address and work on together and those issues that NRM organisations need to address separately. Addressing the common and region specific issues will lead to the development of new knowledge and tools that are useful for the NRM organisations and can assist them with updating their NRM plans.

Through our innovative co-research approach which is supported by a dedicated knowledge broker employed for this project we are well equipped for this task. In particular, since our co-research approach supports collective learning through regular and transparent, two-way communication, we are well positioned to develop adaptive NRM plans that can be updated when new knowledge is generated.

\section{ACKNOWLEDGMENTS}

The Wet Tropics Cluster project is majority funded by the Australian Government's Clean Energy Future Plan. Further support is provided by James Cook University, CSIRO's Climate Adaptation Flagship and the Reef and Rainforest Research Centre via National Environment Research Program funding.

\section{REFERENCES}

Armitage, D., Marschke, M., and Plummer, R. (2008) Adaptive co-management and the paradox of learning. Global Environmental Change 18, 86-98.

Australian Government (2012). Clean Energy Future. http://www.cleanenergyfuture.gov.au/ (accessed $12 / 08 / 2013$ )

Bohnet, I.C. (2010). Integrating social and ecological knowledge for planning sustainable land- and seascapes: experiences from the Great Barrier Reef region, Australia. Landscape Ecology, 25, 1201-1218.

Bohnet, I. C., and Pert, P. (2010). Patterns, drivers and impacts of urban growth: A study from the Cairns region, Queensland, Australia from 1952-2031. Landscape and Urban Planning, 97, 239-248.

Bohnet, I. C., Roebeling, P., Williams, K., Holzworth, D., Van Grieken, M., Pert, P., Kroon, F., Westcott, D., and Brodie, J. (2011). Landscapes Toolkit - An integrated modelling framework to assist stakeholders in exploring options for sustainable landscape development. Landscape Ecology, 26, 1179-1198. 
Ceccarelli, D.M., Richards, Z.T., Pratchet, M.S., and Cvitanovic, C. (2011). Rapid increase in coral cover on an isolated coral reef, the Ashmore Reef National Nature Reserve, north-western Australia. Marine and Freshwater Research, 62, 1214-1220.

Cook, N.C., Hockings, M., and Carter, R.W. (2010). Conservation in the dark? The information used to support management decisions. Frontiers in Ecology and the Environment, 8, 181-186.

Crowley, G., Dale, A., Turton, S., and Bennett, D. (2013). Science to inform Climate Change Planning in North Queensland. Workshop report. The Cairns Institute and Environmental Science, Geography \& Sustainability, School of Earth \& Environmental Sciences, James Cook University.

Dale, A., McKee, J., Vella, K., and Potts, R. (2013). Carbon, biodiversity and regional natural resource planning: towards high impact next generation plans. Australian Planner, DOI: 10.1080/07293682.2013.764908.

Dunlop M., Hilbert D.W., Ferrier S., House, A., Liedloff, A., Prober, S.M., Smyth, A., Martin, T., Harwood, T., Williams, K., Fletcher, C., and Murphy, H. (2012). The Implications of Climate Change for Biodiversity Conservation and the National Reserve System. Report prepared for the Department of Sustainability, Environment, Water, Population and Communities, and the Department of Climate Change and Energy Efficiency. CSIRO Climate Adaptation Flagship, Canberra.

Green, D. (2006). Climate Change and Health: Impacts on Remote Indigenous Communities in Northern Australia. CSIRO Marine and Atmospheric Research Paper 012. ISBN 1921232315.

Green, D. Alexander, L., Mclnnes, K., Church, J., Nicholls, N., and White, N. (2009). An assessment of climate change impacts and adaptation for the Torres Strait Islands, Australia. Climate Change, DOI 10.1007/s10584-009-9756-2.

Hilbert, D.W., Ostendorf, B., and Hopkins, M. (2001). Sensitivity of tropical forests to climate change in the humid tropics of North Queensland. Austral Ecology 26, 590-603.

Jahn, T., Bergmann, M., and Keil, F. (2012). Transdisciplinarity: Between mainstreaming and marginalization. Ecological Economics 79, 1-10.

Lane, M., Robinson, C., and Taylor, B. (2009). Contested country: local and regional natural resources management in Australia, pp.250. CSIRO, Collingwood, Australia.

Lang, D.J., Wiek, A., Bergmann, M., Stauffacher, M., Martens, P., Moll, P., Swilling, M., and Thomas, C.J., (2012). Transdisciplinary research in sustainability science: practice, principles, and challenges. Sustainability Science, Supplement 1, 25-43

McIntre-Tamwoy, S., Fuary, M., and Buhrich, A. (2013). Understanding climate, adapting to change: indigenous cultural values and climate change impacts in North Queensland. Local Environment 18 (1), 91-109.

National Sea Change Taskforce (2013). Newsletter, April 2013. National Sea Change Taskforce. Neutral Bay, New South Wales.

NERP (National Environmental Research Program) (2012). Tropical Ecosystems Hub. http://www.nerptropical.edu.au/ (accessed 12/08/2013)

Ormerod, S.J., Barlow, N.D., Marshall, E.L.P., and Kerby, G. (2002). The uptake of applied ecology. Journal of Applied Ecology 39, 1-7.

Pert, P., Scott, L., and Hill, R. (2013). An interactive tool for capturing social and ecological dynamism in conservation prioritization. Landscape and Urban Planning, 114, 80-91.

Petheram, L., Zander, K.K., Campbell, B.M., High, C., and Stacey, N. (2010). 'Strange changes': Indigenous perspectives of climate change and adaptation in NE Arnhem Land (Australia). Global Environmental Change-Human and Policy Dimensions 20 (4), 681-692.

Possingham, H. (2009). Dealing with 'The Great Divide': A tacit assumption or a universal truth? Decision Point, 28, 2-3.

Williams, S.E., L.P. Shoo, J.L. Isaac, A.A. Hoffman, and G. Langham. (2008). Towards an Integrated Framework for Assessing the Vulnerability of Species to Climate Change. PLoS Biology 6 (12), 26212626. 